\title{
A perspectiva paleontológica no ensino da História Natural e em areas afins
}

THE PALEONTOLOGICAL PERSPECTIVE IN THE TEACHING OF NATURAL HISTORY AND RELATED AREAS

Cristianini Trescastro Bergue

Bolsista PNPD-CAPES. Progr. Pós-Grad. Geociências, Univ. Fed. Rio Grande do Sul. Porto Alegre, RS.

ABSTRACT: Paleontology presents approaches significantly different in the geosciences and biosciences, and its teaching usually assumes practical outlook. In the proposal of teaching herein discussed, based both on transversality and on the so-called Lipps Diagram, paleontology is assumed as a theme instead of a discipline. Moreover, it is claimed that the paleontological perspective would be able to transcend the natural history and pervade a broader range of knowledge fields. This teaching proposal emerges from the analysis of the foremost attributes classically adopted in fossils definition, i.e. age and size. The influence of these attributes in the paleontology are discussed mainly in relation to the institution of disciplines such as micropaleontology, vertebrate paleontology, paleobotany and invertebrate paleontology. The proposal presented in this work upholds that the broadening of the paleontological perspective in the university education, not only in Natural History but also in areas where it is not usually present nowadays, such as Astronomy and Ecology, might prompt useful reflections to the improvement of the teaching in science.

\section{Manuscrito:}

Recebido: 25/02/2014

Corrigido: 16/03/2016

Aceito: 21/03/2016

Citation: Bergue C.T. 2017. A perspectiva paleontológica no ensino da História Natural e em áreas afins. Terræ Didatica, 12(2):93-100. <http:// www.ige.unicamp.br/terraedidatica/>

Keywords: transversality, Natural History, Lipps Diagram, scientific education.

\section{Introdução}

Você já parou para pensar quantas vezes perguntas relativas ao aparecimento ou extinção de um animal ou planta já soaram aos seus ouvidos? Elas certamente incluíram desde as mais pueris e despropositadas como "Quem surgiu primeiro: o ovo ou a galinha?" até as mais complexas como "Quando surgiu o homem?”. Estas e outras questões congêneres guardam em si, porém, dois aspectos pertinentes ao propósito deste trabalho. Primeiro, envolvem a abstrata dimensão tempo e, segundo, são recorrentes geração após geração, talvez como resultado da intrínseca curiosidade humana. O último aspecto, em particular, é de especial importância por estar relacionado ao ensino científico.

Assume-se que a vida na Terra surgiu há aproximadamente 3,8 Ga (Schopf 2006) e a partir de então diversificou-se por intermédio da evolução biológica. Evidências deste continuum são fornecidas pelos fósseis e por relíquias anatômicas dos organismos viventes (Shubin 2008). A Paleontologia, definida como o estudo do registro fóssil, possui enfoques diferentes nas Geociências ou nas Biociências em razão de como o registro fóssil foi interpretado e de como o conhecimento assim adquirido passou a integrar o fazer científico e técnico.

O escopo da Paleontologia pode tornar-se difuso perante a patente imprecisão do conceito de fóssil. Há casos em que as características de um determinado espécime não deixam dúvidas dessa condição, como por exemplo um crânio permineralizado ou um tronco de madeira no qual houve substituição por sílica. A análise visual, nesses casos, é suficiente para um especialista defini-los como fósseis. Em outras situações, porém, alterações de forma e composição são imperceptíveis, apesar da idade do espécime. Então, a partir de qual momento um resto orgânico, ou de atividade biológica, é considerado fóssil? No clássico texto Paleontologia Básica, Mendes (1988) comenta que o conceito de fóssil pode ser variável e mesmo arbitrário. Nele, o autor adota o limite entre o tempo "histórico" e "pré-histórico" (6.000 anos) para definir uma estrutura orgânica como fóssil. Cassab (2010), por outro lado, apresenta uma definição alternativa na qual apenas vestígios com mais de 11.000 anos devem 
ser considerados fósseis. É fundamental atentarmos nesta discussão sobre a existência, posto que excepcional, de preservações que não implicam a mineralização ou recristalização das partes duras, como os mamíferos preservados no asfalto ou insetos no âmbar (Raup \& Stanley 1978). Depreende-se, portanto, que a idade é o principal atributo de um fóssil, constituindo característica necessária e suficiente para defini-lo.

A discussão seria destituída de propósito se a Paleontologia e a Neontologia não constituíssem áreas do conhecimento distintas nos moldes da ciência moderna. Se tomarmos a Paleontologia sob seu aspecto essencial, ou seja, o estudo da vida baseado no registro fóssil, a única diferença entre ela e a Neontologia seria o tempo, como denotam os prefixos paleo e neo. Esta, porém, seria uma forma extremamente simplista de análise na qual se desconsideraria que a dicotomia Paleontologia-Neontologia surgiu quando a essência dos fósseis passou a ser compreendida. Fundamentou-se, portanto, nas distintas formas de obtenção e interpretação de dados. A forma de entender e explicar a origem dos fósseis foi (e continua sendo) influenciada pelo pensamento religioso, além do desconhecimento sobre a vastidão do Tempo Geológico (Gould 1991). Organismos fósseis e viventes, portanto, foram outrora considerados entidades de criação simultânea cuja idade era restrita ao período bíblico.

Como resultado, ou por influência desse pensamento, o estudo dos seres vivos, fossem eles fósseis ou viventes, integrou por muito tempo uma única e ampla área do conhecimento, denominada História Natural. Em textos didáticos antigos como Langlebert (1925), por exemplo, a história natural é definida como:

"a sciencia que tem por fim o estudo de todos os corpos brutos ou vivos espalhados na superfície da terra ou que constituem sua massa (...); a história natural pesquisa a origem, o modo de formação e de crescimento dos corpos; estuda suas fórmas externas, sua organização ou sua estructura interna, sua distribuição geographica, em uma palavra, todos os caracteres que podem servir para distinguil-os uns dos outros" (Langlebert 1925, p. 1, mantida a grafia original).

O autor destaca que a História Natural foca-se no estudo das formas, organização e distribuição dos corpos vivos e brutos. Ou seja, possui grande ênfase na classificação. Este modelo de organização do conhecimento influenciou também a estrutura da educação superior brasileira. História Natural era a designação de um curso superior existente até a o início da década de 1970 que formava profissionais com conhecimentos amplos em Geociências e Biociências para atuação nas áreas de pesquisa e ensino. O desenvolvimento científico subsequente levou à ampliação desta área do conhecimento e consequentemente, sua fragmentação, bem como do curso de graduação homônimo. As disciplinas biológicas que o compunham, acrescidas de outras, originaram cursos de Biociências. Contudo, História Natural, sob o ponto de vista semântico, continua sendo a melhor e mais objetiva designação dada ao conjunto de ciências que se ocupam do estudo da Terra e de seus seres vivos, equivalente, por exemplo, à ciências humanas. Seu uso, portanto, é incentivado e adotado neste texto.

\section{Sobre a trajetória (natural) entre conhecer 0 passado e dele utilizar-se}

Peculiarmente, a Paleontologia permaneceu como integrante dos cursos de Geociências e Biociências, numa singular coexistência sustentada pelos escopos ligeiramente distintos que adotou em cada um. A Paleontologia em seu caráter mais essencial e talvez primevo, detinha-se no estudo do fóssil exclusivamente como um testemunho da vida extinta. Com o passar do tempo, estes conhecimentos revelaram-se úteis para fins práticos, quais sejam, a datação e caracterização de ambientes passados.

$\mathrm{Na}$ percepção de um geocientista os fósseis são componentes ocasionais de uma determinada rocha, a qual é seu objeto de estudo por excelência. Até o início do século XX eram o único recurso disponível para a datação de rochas (Press et al. 2006) e ainda hoje continuam sendo um método confiável e relativamente pouco oneroso para este propósito. Conhecimentos paleontológicos são, portanto, essenciais ao geocientista. Já para o biocientista, o interesse principal desta investigação reside nas características morfológicas do fóssil que permitem sua classificação taxonômica e relações filogenéticas. Muitos trabalhos paleontológicos antigos, inclusive, detinham-se essencialmente na descrição do espécime, desconsiderando em maior ou menor grau, a sucessão ou orientação dos fósseis nas rochas (Holz \& Simões 2002, p. 34).

Naturalmente, essas diferentes percepções passaram a influenciar o ensino da Paleontologia nas universidades, embora nem sempre encontre- 
-se presente nos currículos. Em decorrência da sua importância instrumental, ele usualmente integra o currículo dos cursos de Geociências. Paradoxalmente, nem sempre está presente nos cursos de Biociências, não obstante a ausência da perspectiva paleontológica na formação acadêmica destes profissionais não possa ser compensada por outros conhecimentos. Assumindo-se que a compreensão da origem e evolução da vida seja possível apenas conhecendo-se a sua história, a Paleontologia mostra-se essencial à formação do biocientista.

\section{0 papel do tema na flexibilização dos conteúdos programáticos}

A formação acadêmica consiste em oferecer conhecimentos, reflexões e práticas que facultarão ao indivíduo o desempenho de uma atividade profissional. Nesse ponto, cabe refletir sobre o significado dos currículos e programas no âmbito do ensino. Os currículos são compostos por disciplinas regulamentares, as quais possuem programas de conteúdos a serem ministrados. Existe, porém, uma margem de flexibilização em uma disciplina conforme o interesse e capacitação do docente (e, também, o interesse dos alunos). Ou seja, o professor é capaz de promover mudanças sem descaracterizar uma disciplina, relacionando seus conteúdos com outros elementos curriculares, tornando-a mais atrativa e, quiçá, facilitando o aprendizado, da disciplina propriamente dita, bem como de outras.

Neste texto refere-se a tema como conhecimentos que podem ser trabalhados em uma disciplina, desde que pertinentes a ela. Os chamados temas transversais propostos para a educação básica (MEC/SEF 1998) permeiam diferentes áreas do saber e conferem maior significado aos conteúdos estudados. Contudo, seus princípios são aplicáveis a qualquer nível educacional, o que permite a adoção da transversalidade no ensino superior. Ensinar Paleontologia numa abordagem transversal, portanto, não implica criar disciplinas específicas e sim integrar a abordagem paleontológica ao ensino dos seres vivos atuais e seus ambientes, desde que isso ocorra de forma a promover um novo significado aos conteúdos ensinados. Nesse sentido, a proposta aqui apresentada para a inclusão da perspectiva paleontológica no ensino superior é equivalente ao "nível de abordagem" proposto por Bergue (2000, p. 146) para o ensino básico.

Num modelo convencional de ensino, a Pale- ontologia é ministrada em disciplinas específicas, de caráter obrigatório ou optativo. Ou seja, uma gama de conhecimentos referentes à história evolutiva dos seres vivos é compartimentalizada em uma ou mais disciplinas. A relação entre conhecimentos paleontológicos e neontológicos no ensino convencional é bastante peculiar, pois enquanto a Paleontologia utiliza exemplos e conceitos de biotas viventes (princípio atualístico), a Neontologia usualmente não faz uso de exemplos paleontológicos. Em suma, a inserção da perspectiva paleontológica, que representa uma visão integral da História Natural, não é usualmente desenvolvida no ensino científico convencional.

Paleontologia, no presente texto, é sustentada como um tema, não uma disciplina. A transversalidade permite que um tema perpasse o programa de outras disciplinas, não meramente como um conteúdo adicional, mas trazendo a ela sua perspectiva. Além disso, observa-se no ensino convencional uma fragmentação desmesurada e artificial, bem como a falta de conexão entre os conteúdos. Tomemos por exemplo o ensino de Zoologia no qual a carga horária destinada ao estudo dos diferentes grupos não é proporcional à diversidade biológica dos mesmos. A abordagem transversal permite que a Paleontologia transcenda as disciplinas dos cursos de Geociências e Biociências, proporcionando sua perspectiva a outras áreas do saber. Neste tipo de abordagem, o ensino da Paleontologia em cursos de Biociências, nos quais a História Natural compõe o cerne curricular, não dependeria da existência de disciplinas específicas.

\section{A possibilidade de mudar e sua razão}

De que forma a perspectiva paleontológica pode contribuir para que um indivíduo aprimore sua compreensão da realidade, objetivo precípuo da Educação? Este deve ser o móvel do professor que busca implementar esta proposta. Deve começar entendendo que a educação não é meramente um processo que vise habilitar o estudante ao exercício de uma profissão. A execução da proposta apresentada neste trabalho constituiria uma opção do docente que, conforme os resultados obtidos, proporia a remodelação formal do programa ou mesmo do currículo.

Cabe ao docente, portanto, inserir a abordagem do tema, dosando-o de forma a evitar que ele se torne mero conteúdo adicional, senão conhecimentos que proporcionem novas percepções ao estudante. 
A profundidade e a abrangência dependerão da carga horária e da capacitação do docente que assume agora de forma mais efetiva seu papel de mediador entre o currículo e os alunos, um agente curricular modelador de conteúdos conforme define Sacristán (2000).

A perspectiva paleontológica possibilita uma nova forma de abordagem do ensino de biologia comparada (sensu Nelson, 1970) bem como de outras áreas do conhecimento, atribuindo-lhe viés histórico. Não agregaria valor algum à uma determinada disciplina se consistisse apenas em acréscimo de conteúdos. Sua razão está na possibilidade de proporcionar uma percepção alternativa sobre a diversidade do mundo vivo ao longo do Tempo Geológico por meio dos conhecimentos paleontológicos a ela agregados. Na proposta seria realçada a percepção de que a vida é um processo contínuo, integrado e que evolui por meio de interações entre a biosfera e a geosfera. A perspectiva paleontológica, portanto, não apenas complementaria, mas facilitaria o entendimento do processo evolutivo.

Naturalmente, não há exigência de formação acadêmica em Paleontologia aos docentes simpáticos a esta proposta, embora isso possa existir e tornar-se um facilitador. Nos demais casos, constituiria uma oportunidade de aprimoramento profissional do professor visto implicar na sua familiarização com conteúdos alheios a sua prática cotidiana. Neste ponto, a criatividade, o interesse da turma e as condições institucionais (p. ex., a existência de paleontólogos na instituição, de um acervo de fósseis, proximidade a jazigos fossilíferos) são fatores que concorrem.

A abrangência da Paleontologia como tema transversal na Educação é ampla e não se restringe à História natural. O professor tem possibilidades de inserir a perspectiva paleontológica em outras áreas do conhecimento. Vejamos alguns exemplos que podem fundamentar propostas de atividades didáticas ou tópicos de aulas.

Botânica/Zoologia. A proposta de transversalidade adequa-se perfeitamente às disciplinas tradicionais de biologia comparada, onde ao estudar um determinado grupo o aluno constataria que sua representatividade em biotas pretéritas poderia ser maior ou menor. $\mathrm{O}$ caso dos braquiópodes (Filo Brachiopoda) é emblemático nesse caso. Há em torno de 335 espécies viventes descritas neste filo o que o caracteriza como pouco expressivo em termos de biodiversidade se comparado a outros como Nematoda, Unirramia ou Mollusca (Brus- ca \& Brusca 2007). Analisando a história evolutiva dos braquiópodes, porém, constata-se que no eopaleozóico eles foram muito diversificados e abundantes, constituindo um importante elemento das biotas bentônicas marinhas. Outro grupo que proporciona uma visão bastante diferente quando visto sob aspecto de sua história evolutiva são os equinodermos. Vê-se, portanto, que ao se agregar a perspectiva paleontológica, obtém-se uma percepção diferente a respeito de um assunto.

A intrínseca relação entre evolução e sistemática torna-se também evidente sob a ótica da paleontologia. A propalada expressão "fóssil vivo" constitui adequado ponto de partida para discussões dessa natureza. A literatura paleontológica eventualmente menciona táxons como Ginkgo (Ginkgophyta: Ginkgoales), Latimeria (Osteichtyes: Sarcopterigii) e Limulus (Chelicerata: Xiphosura) como fósseis vivos. Entretanto, deveria a expressão ser aplicada a táxons supraespecíficos ou restringir-se a espécies? Emig (2003) discorre sobre esse instigante assunto com base em um dos mais célebres "fósseis vivos", o braquiópode Lingula, destacando a importância da taxonomia na compreensão da distribuição cronoestratigráfica das espécies desse gênero.

Outro assunto atinente à relação taxonomia-evolução é a extinção dos dinossauros. Seriam eles seres extintos, ou este status é fruto de uma conceituação? Conforme se define dinossauro (incluindo ou não formas avianas de arcossáurios) eles podem ou não ser considerados extintos (Anelli 2010). Outro tema propício à discussão entre evolução e sistemática em sala de aula refere-se aos artrópodes. Vistos em determinada época como um táxon, o conhecimento paleontológico revelou que a artropodização foi um processo difundido a partir do Eocambriano, quando diversos filos de animais com apêndices articulados surgiram, dos quais apenas três ainda existem: Unirramia, Chelicerata e Crustacea.

Ecologia. A perspectiva paleontológica pode abranger também áreas do conhecimento como a Oceanografia, Ecologia e Geografia. Ela permite reflexões sobre os climas do passado que são usuais tanto em disciplinas mais generalistas como paleoclimatologia e paleoecologia, como mais específicas, como paleoceanografia e paleolimnologia. A ocorrência e o modo de preservação revelam conexões causais entre o clima e o registro fóssil. Disciplinas de Ecologia, portanto, podem ser enriquecidas com informações paleontológicas ao abordarem conteúdos relativos a climas do passado. Compreender 
os processos de fossilização ou teorias a respeito da origem da vida demanda conhecimentos amplos que favorecem a inclusão da perspectiva paleontológica nas Ciências Ambientais.

A compreensão dos padrões de ocorrência dos organismos atuais sustenta-se no entendimento das mudanças ocorridas na Terra e por este motivo é intimamente ligado à Paleontologia. Exemplos de floras e faunas pretéritas, de províncias faunísticas, são observados no registro fóssil e constituem, portanto, subsídios para o ensino integrado da Biogeografia e da Paleobiogeografia. Biogeografia e Evolução são igualmente tópicos conexos e neste ponto oportuniza-se novamente a possibilidade de trazer a perspectiva paleontológica à biogeografia.

Antropologia/Arqueologia. Os hominídeos fósseis são estudados por um ramo da Antropologia física denominado Paleoantropologia, o qual trata de um dos assuntos mais efervescentes do mundo acadêmico: a evolução humana. Isto é prontamente constatado pela repercussão gerada pela descrição de uma nova espécie de hominídeo, ou de um fóssil que recue a idade de origem da família, como o caso do Ardipithecus (White et al. 1994; Berger et al. 2015). A espécie mais antiga de Homo tem aproximadamente $2,5 \mathrm{Ma}$, enquanto a família Hominidae tem uma história de aproximadamente, $6 \mathrm{Ma}$. Considerando que a evolução dos hominídeos foi influenciada por eventos climáticos e que seu estudo é baseado num precário registro fóssil, percebe-se o fértil terreno para o estabelecimento da perspectiva paleontológica na antropologia. A arqueologia, por sua vez, trata essencialmente de vestígios da cultura material humana que em alguns casos podem incluir organismos fósseis pleistocênicos (Kern 1991). Vestígios humanos propriamente ditos, não são usualmente tratados como fósseis, mesmo que datem do Pleistoceno tardio, como os provenientes da região de Lagoa Santa, MG (Prous 2006). Por quê? Que benefícios e prejuízos esta segregação traz ao ensino científico? Apesar da distinção entre estas duas áreas de pesquisa estar bem definida na ciência moderna, elas compartilham muitos princípios metodológicos podendo, portanto, beneficiarem-se mutuamente também no âmbito do ensino. Alguns conceitos das Geociências como Tafonomia e Estratigrafia encontram-se incorporados à Arqueologia, com as devidas adaptações (Bahn 2004) indicando uma possibilidade e tendência de aproximação.

Astronomia. A busca por vida em outros planetas, bem como teorias a respeito de sua exis- tência, a chamada Astrobiologia, é auxiliada pelo conhecimento acerca das primeiras formas de vida terrestres (Fairchild et al. 2012). Assume-se que as biotas primordiais podem servir de referência para a detecção de vida - existente ou extinta - em outros planetas. A morfologia, fisiologia, e modo de existência dos primeiros habitantes da Terra eram adaptados a condições ambientais substancialmente diferentes das atuais, porém similares às observadas em outros planetas ou seus satélites. Essa relação intrínseca, inclusive, é constatada pelo fato de projetos de pesquisa do biólogo Carl Woese, autor da proposta de divisão da vida nos domínios organizacionais Archaea, Bacteria e Eucarya, terem sido financiados pela Agência Espacial Norte-Americana (NASA).

\section{A micropaleontologia: um caso especial}

Ao assumirmos que a transversalidade atuaria como facilitadora do entendimento da origem e evolução da vida, devemos não apenas conceber a Paleontologia como saber insubstituível a este propósito, mas também rever a forma como é ensinada. A aproximação entre a Paleontologia e a Neontologia é exequível, conforme discutido anteriormente, na História Natural e pode abranger inclusive áreas afins. Entretanto, o ensino da Paleontologia adota uma divisão de grupos conservadora e artificial, usualmente, subdividido para fins didáticos em Paleontologia de Vertebrados, Paleontologia de Invertebrados, Paleobotânica e Micropaleontologia. Esta última presta-se bem à reflexão sobre a segmentação do conhecimento na pesquisa e seu reflexo no ensino.

Define-se como microfóssil um resto orgânico fossilizado cujo estudo demanda recursos de microscopia de alta magnificação. Como definiu Kesling (1969), tudo o que os antigos paleontólogos não conseguiam examinar com lentes de mão, era posto de lado para ser estudado por "especialistas com microscópios". Os microfósseis são os principais elementos do que usualmente se refere como "paleontologia aplicada" ou "paleoecologia econômica" (Howe 1971). As denominações resultam do potencial que apresentam para a solução de problemas geocientíficos, em particular a caracterização de paleoambientes e datação de rochas.

Pelo status adquirido na Geologia, a Micropaleontologia figurou ou figura como disciplina obrigatória no currículo de muitos cursos de Geociências no Brasil. Mas, afinal, existe realmente sustentação 
teórica para a Micropaleontologia? Até que ponto o caráter instrumental de uma disciplina pode definir o escopo de uma ciência? Um clássico exemplo desta relação é a forma como a expansão do uso do petróleo como recurso energético primordial a partir da Primeira Guerra Mundial fomentou e modelou a pesquisa de determinados grupos fósseis, levando à consagração da Micropaleontologia (Lipps 1981, Bergue 2010). Traçando um paralelo com o surgimento da Biologia Molecular em meados do século XX, observa-se que a institucionalização da micropaleontologia foi consequência de sua aplicabilidade à exploração de petróleo, realçando a relação entre a institucionalização de uma linha de pesquisa e sua fecundidade conforme aborda Nouvel (2001).

Diversas são as formas de constatarmos e refletirmos sobre o efeito da segmentação do conhecimento no ensino científico e, consequentemente, na formação dos cidadãos. $\mathrm{O}$ seguinte texto, que constituiu o germe desse trabalho, permite-nos refletir sobre o real significado da micropaleontologia no âmbito das Geociências. Como sugestão de atividade, apresente-o aos alunos e peça que complementem o relato nele contido:

Diante de mim estava o bloco de rocha ao qual dedicaria aquele dia de trabalho. Era uma rocha avermelhada, de textura muito fina. Um folhelho, segundo a boa classificação geológica. Em algumas partes suas finas camadas eram facilmente removíveis e sob elas conchas apareciam em abundância. Algumas inteiras, outras amassadas, mas a maioria estava mesmo quebrada. Em alguns níveis da rocha estas conchas eram tão abundantes que tornava-se impossível remover uma sem danificar a outra que estava ao lado. Em outros níveis, porém, eram raras e mesmo ausentes.

Coletar aqueles fósseis não era tão difícil. Exigia apenas um pouco de paciência, pois muitos eram frágeis e quebravam-se facilmente. Com um instrumento metálico pontiagudo eu escavava pacientemente em torno do espécime. Depois, com um lento e cuidadoso movimento, os alavancava e extraía da rocha. Também cuidadosamente, os acondicionava em um recipiente de papelão. Mas a quantidade de fósseis era tamanha que logo cobriu o fundo daquele recipiente.

Exauridos os fósseis de uma camada, varria a superfície da rocha meticulosamente com um pincel. E com o auxílio da alavanca, erguia uma nova camada e recomeçava o trabalho. Num certo ponto da coleta, porém, o trabalho tornou-se especial!
Descobri uma espécie de cova da qual surgiram muitos fósseis agrupados de forma mais ou menos compacta. Ao contrário dos outros que foram coletados nos planos horizontais, brancos, quebrados, nesta cova foram recuperados espécimes inteiros. Alguns tinham uma cor escura quase preta. Fui retirando-os com imensa alegria, um após o outro. Até que eles também exauriram-se, então (...).

Quantas interpretações diferentes surgiriam? O mais fascinante é que ele foi elaborado a partir de uma coleta de fósseis sob... um estereomicroscópio! As conchas coletadas não eram de moluscos biválvios ou de braquiópodes, mas de ostracodes, crustáceos que, em muitos casos, possuem menos de $1 \mathrm{~mm}$ quando adultos. E o presumido afloramento era na realidade um fragmento de rocha de aproximadamente $2 \mathrm{~cm}$ de comprimento. A alavanca metálica, uma simples agulha histológica e a varrição dos fragmentos realizada com um finíssimo pincel $\mathrm{n}^{\circ} 000$

O fragmento de folhelho vermelho da Formação Brejo Santo (Bacia do Araripe) e seus ostracodes, nos quais se baseia o capcioso relato exemplifica bem a influência do atributo tamanho na Paleontologia, o qual consagrou o termo microfóssil. Na realidade, a percepção de tamanho modela nossa interpretação da realidade, inclusive naquilo que seria a mais racional das atividades humanas, a ciência. Ainda que a grande maioria das formas de vida conhecidas seja microscópica, a influência do tamanho na percepção que temos do mundo vivo arraigou-se de forma indelével. Termos tão usuais e relativos como "micróbio" e "microorganismo" vão, certamente, figurar por muito tempo em nosso vocabulário.

A percepção dos fatos e a construção intelectual dela resultante varia conforme as tecnologias disponíveis de observação e mensuração. No caso da história natural esses recursos passaram ao longo do tempo dos simples microscópios de mão até os sofisticados microscópios eletrônicos. Os princípios da Paleontologia, porém, são universais a qualquer grupo fóssil, independente de tamanho. A despeito de sua artificialidade, a Micropaleontologia institucionalizou-se como disciplina em consequência de sua aplicabilidade direta. Conteúdos abordados em disciplinas de Micropaleontologia, porém, poderiam ser ministrados em outras disciplinas paleontológicas. Polens, esporos, carófitas, diatomáceas e nanofósseis calcários, por exemplo, são temas afins à paleobotânica; foraminíferos, ostracodes e radiolários, à paleontologia de invertebrados. 


\section{Muito além do ensino, uma nova cultura científica}

Como fazer uma remodelação de tamanha envergadura? Essa ação implica a adoção de uma visão integradora, tanto na percepção sobre o mundo vivo, quanto na forma de organizar a biodiversidade em diferentes disciplinas. Um autor em especial já apresentou um modelo alternativo de ensino de paleontologia. Lipps (1981) propôs a abordagem paleontológica dos diferentes grupos conforme o diagrama de cinco reinos de Whitaker (1969) (Fig. 1). Dividiu o estudo dos fósseis em Paleontologia de Moneras (Reino Monera), Paleontologia de Protistas (Reino Prototista), Paleontologia de Invertebrados/ Vertebrados (Reino Animalia), Paleomicologia (Reino Fungi) e Paleobotânica (Reino Plantae). Nele não figura a Micropaleontologia, o que não o torna menos completo, e o estudo dos fósseis adquire um teor mais natural e integrado.

Apesar de não ter sido amplamente apreciada pela comunidade paleontológica, o diagrama de cinco reinos de Whitaker (1969) coaduna-se com a ideia de remodelamento do ensino da história natural aqui proposto. Por este motivo, uma atualização do "Diagrama de Lipps" é aqui apresentada com base no trabalho de Woese et al. (1990), no qual foi proposta a divisão dos seres vivos nos domínios Archaea, Bacteria e Eucarya (Fig. 2). A essência do diagrama, contudo, é a mesma, consistindo na adoção de termos paleontológicos equivalentes aos neontológicos na denominação das disciplinas. Além disso, permite aproximar as abordagens paleontológica e neontológica sob uma proposta de classificação mais natural.

O que é proposto neste trabalho, em síntese, é

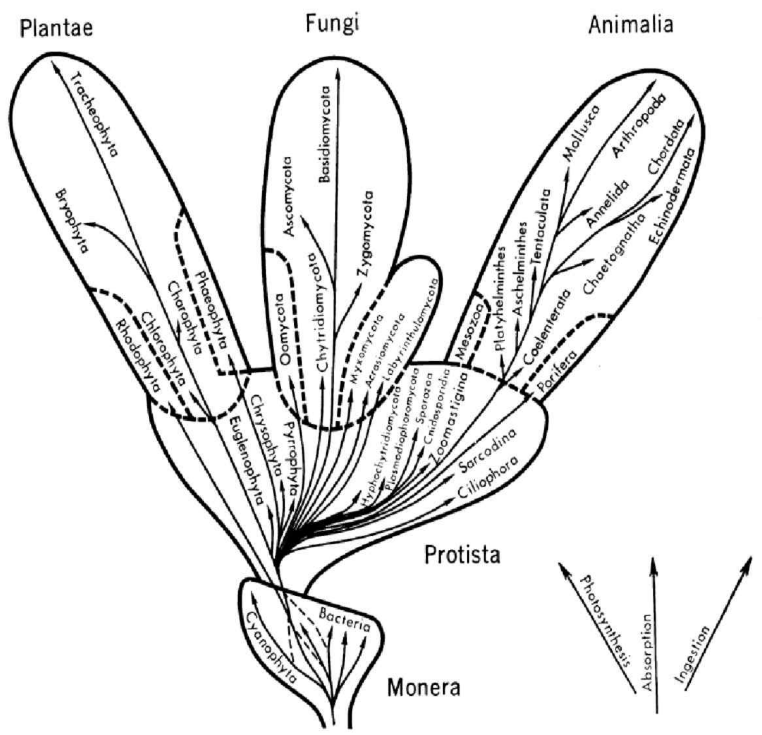

Figura 1. Diagrama de Whitaker (1969) representando a organização do mundo vivo em cinco reinos: Monera, Prototista, Fungi, Animalia e Plantae

\section{Agradecimentos}

O autor expressa seu agradecimento ao prof. Rualdo Menegat (IG-UFRGS) pela crítica e sugestões oferecidas na versão original deste manuscrito. Agradeço ainda à profa. Amelia Calonge Garcia (Universidad de Alcalá, Espanha) cuja revisão e comentários muito contribuíram para o aprimoramento deste trabalho. O autor manifesta ainda seu agradecimento ao Programa de Pós-Graduação em Geociências da Universidade Federal do Rio Grande do Sul (PPGGeo/UFRGS) e a Coordenação de Aperfeiçoamento de Pessoal de Nível Superior pela concessão da bolsa Capes/PNPD. a inserção da perspectiva paleontológica na educação superior por meio da transversalidade, pois constitui fonte insubstituível de conhecimentos necessários à formação de geocientistas e biocientistas. Além disso, essa abordagem poderia igualmente abranger a Educação Básica, contribuindo para a construção de uma nova cultura científica nas instituições de ensino do país.

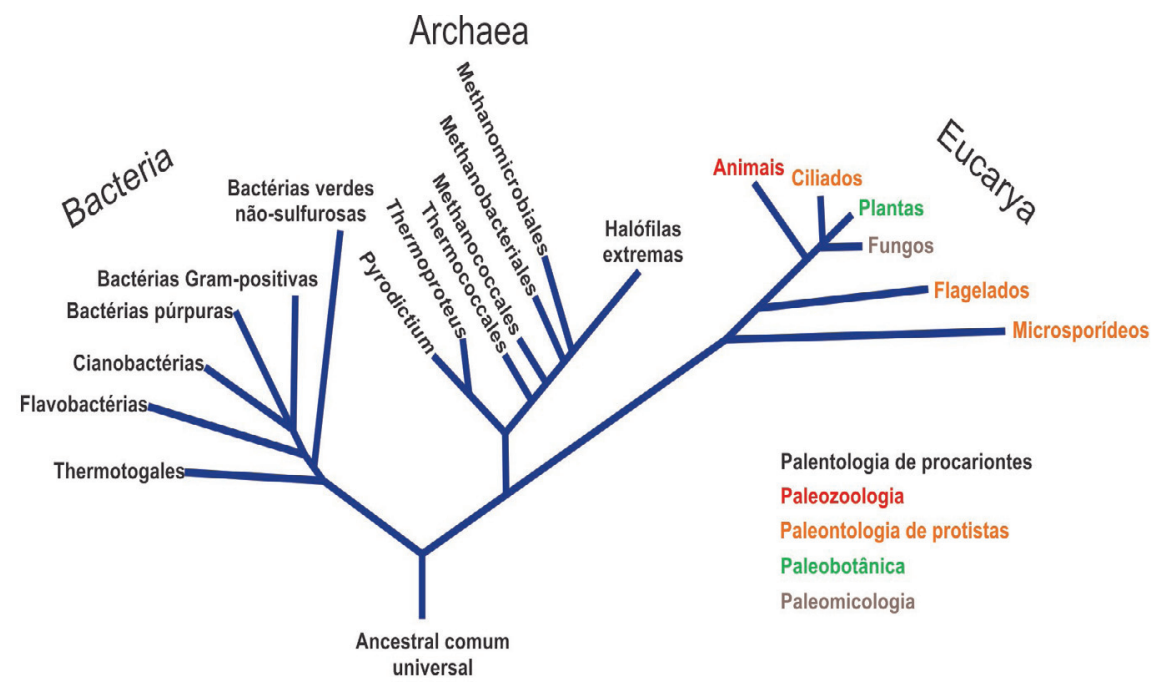

Figura 2. Adaptação do diagrama de Lipps (1981) baseado no trabalho de Woese et al. (1990) 


\section{Referências}

Anelli E.L. 2010. O guia completo dos dinossauros do Brasil. São Paulo: Ed. Peirópolis. 222 p.

Bahn P. 2004. Dictionary of archaeology. Suffolk: Ed. Penguin. $526 \mathrm{p}$.

Berger L.R., Hawks J., De Ruiter D.J., Churchill S.E., Schmid P., Delezene L.K., Kivell T.L., Garvin H.M., Williams S.A., DeSilva J.M., Skinner M.M., Musiba C.M., Cameron, N., Holliday T.W., Harcourt-Smith, W., Ackermann, R.R., Bastir M., Bogin B., Bolter D., Brophy J., Cofran Z.D., Congdon K.A., Deane A.S., Dembo M., Drapeau M., Elliott M.C., Feuerriegel H.M., Garcia-Martinez D., Green D.J., Gurtov A., Irish J.D., Kruger A., Laird M.F., Marchi D., Meyer M.R., Nalla S., Negash E.W., Orr C.M., Radovcic D., Schroeder L., Scott J.E., Throckmorton Z., Tocheri M.W., VanSickle C., Walker C.S., Wei P., Zipfel B. 2015. Homo naledi, a new species of the genus Homo from the Dinaledi Chamber, South Africa. eLife 2015; 4:e09560. doi: 107554/eLife.09560.

Bergue C.T. 2000. Uma abordagem sobre o ensino de paleontologia em nível fundamental e médio. In: Dos Santos, L.H.S. org. 2000. Biologia dentro e fora da escola. Meio ambiente, estudos culturais e outras questões. Cadernos de educação básica 6. Porto Alegre: Ed. Mediação. p. 145-156.

Bergue C.T. 2010. Agulhas e pincéis: as relações entre a paleontologia e a neontologia no estudo dos ostracodes (Crustacea: Ostracoda). Terrae Didatica 6(1):09-24. URL: http://www.ige.unicamp.br/terraedidatica/

Brusca R.C. \& Brusca G.J. 2007. Invertebrados. Rio de Janeiro: Ed. Guanabara Koogan. 968 p.

Cassab R.C.T. 2010. Objetivos e princípios. In: Carvalho, I.S. ed. 2010. Paleontologia vol.1. Conceitos e métodos. Rio de Janeiro: Ed. Interciência. p. 3-11.

Emig C.C. 2003. Proof that Lingula (Brachiopoda) is not a living-fossil, and emended diagnosis of the family Lingulidae. Carnets de Géologie, 2003(1):1-8

Fairchild T.R., Sanchez E.A.M., Pacheco M.L.A.F., Leme J.M. 2012. Evolution of Precambrian life in the Brazilian geological record. Intern. J. Astrobiology. doi: 10.1017/ S1473550412000183.

Gould S.J. 1991. Seta do tempo, ciclo do tempo: mito e metáfora na descoberta do tempo geológico. São Paulo: Ed. Schwarcz. $221 \mathrm{p}$.
Holz M., Simões M.G. 2002. Elementos Fundamentais de Tafonomia. Porto Alegre: Ed. UFRGS, 231 p.

Howe H.V. 1971. Ecology of American torose Cytherideidae. Bulletin du Centre des Recherches Pau - SNPA, 5:349-359.

Kern A.A. 1991. Origem da ocupação pré-histórica do Rio Grande do Sul na transição Pleistoceno-Holoceno. In: Kern A.A. org. 1991. Arqueologia pré-histórica do Rio Grande do Sul. Porto Alegre: Ed. Mercado Aberto. p. 89-102.

Kesling R.V. 1969. Micropaleontology. Mostly a little about much concerning many of the little. Proceedings of the North American Paleontological Convention, p. 27-39.

Langlebert J. 1925. Historia natural. Rio de Janeiro: Ed. Garnier. 530 p.

Lipps J.H. 1981. What, if anything, is micropaleontology? Paleobiology, 7(2):167-199.

MEC/SEF (Secretaria da Educação Fundamental/MEC). 1998. Parâmetros Curriculares Nacionais: temas transversais. Brasília: MEC/SEF.

Mendes J.C. 1988. Paleontologia básica. São Paulo: EDUSP. $347 \mathrm{p}$.

Nelson G.J. 1970. Outline of a theory of comparative biology. Systematic Zoology, 19(4):373-384.

Nouvel P. 2001. A arte de amar a ciência. São Leopoldo: Ed. Unisinos. $194 \mathrm{p}$.

Prous A. 2006. O Brasil antes dos brasileiros. A pré-história do nosso país. Rio de Janeiro: Jorge Zahar Ed. 141p.

Raup D.M. \& Stanley S.M. 1978. Principles of paleontology. San Francisco: WH Freeman \& Co. 481p.

Sacristán G.J. 2000. O currículo: uma reflexão sobre a prática. Porto Alegre: Ed. Artmed. 352p.

Schopf J.W. 2006. Fossil evidence of archean life. Philosophical Transactions of the Royal Society, 361:869-885.

Shubin N. 2008. A história de quando éramos peixes. Rio de Janeiro: Ed. Campus. 191p.

Whitaker R.H. 1969. New concepts of Kingdoms of Organisms. Science, 163:150-160.

White T.D., Suwa G., Asfaw B. 1994. Australopithecus rami$d u s$, a new species of early hominid from Aramis, Ethiopia. Nature, 371:306-312.

Woese C.R., Kandler O., Wheelis M.L. 1990. Towards a natural system of organisms: Proposal for the domains Archaea, Bacteria, and Eucaria. Proc. Nat. Acad. Sciences USA, 87:4576-4579.

Resumo: A Paleontologia possui abordagens significativamente diferentes nas Geociências e nas Biociências e seu ensino assume, geralmente, uma perspectiva instrumental. Na proposta de ensino aqui discutida, a qual baseia-se na transversalidade e no chamado Diagrama de Lipps, a Paleontologia é assumida como um tema e não uma disciplina. Além disso sustenta-se que a perspectiva paleontológica pode transcender a História Natural e abranger um espectro mais amplo de conhecimentos. Esta proposta de ensino baseia-se na análise dos principais atributos adotados classicamente para a definição dos fósseis, ou seja, a idade e 0 tamanho. Suas influências na Paleontologia são discutidas principalmente em relação à criação de disciplinas como a micropaleontologia, paleontologia de vertebrados, paleobotânica e paleontologia de invertebrados. A proposta apresentada neste trabalho sustenta que a ampliação da perspectiva paleontológica na educação superior, não apenas na História Natural mas em áreas onde não é usualmente abordada atualmente, como a Astronomia e a Ecologia, pode promover reflexões úteis ao aperfeiçoamento do ensino de ciências.

PALAVRAS-CHAVE: transversalidade, História Natural, Diagrama de Lipps, ensino científico. 